\title{
Correction to: Using hybrid artificial intelligence approach based on a neuro-fuzzy system and evolutionary algorithms for modeling landslide susceptibility in East Azerbaijan Province, Iran
}

\author{
Solmaz Abdollahizad ${ }^{1} \cdot$ Mohammad Ali Balafar $^{1,2} \mathbb{D} \cdot$ Bakhtiar Feizizadeh $^{1,3} \cdot$ Amin Babazadeh Sangar $^{1} \cdot$ \\ Karim Samadzamini ${ }^{4}$
}

Published online: 14 September 2021

(c) Springer-Verlag GmbH Germany, part of Springer Nature 2021

\section{Correction to: Earth Science Informatics}

https://doi.org/10.1007/s12145-021-00644-z

In the original published version of this article, the authors Mohammad Ali Balafar and Bakhtiar Feizizadeh another affiliations were not presented under their names. The second affiliations should have been "Department of IT and Computer Engineering, Urmia Branch, Islamic Azad University, 57169-63896 Urmia, Iran”

The original article has been corrected.
Publisher's note Springer Nature remains neutral with regard to jurisdictional claims in published maps and institutional affiliations.

The original article can be found online at https://doi.org/10.1007/ s12145-021-00644-z.

Mohammad Ali Balafar balafarila@tabrizu.ac.ir

Solmaz Abdollahizad

Solmaz.abdollahzad@iaurmia.ac.ir

Bakhtiar Feizizadeh

Feizizadeh@tabrizu.ac.ir

Amin Babazadeh Sangar

Bsamin2@liveutm.onmicrosoft.com

Karim Samadzamini

samadzamini@ucna.ac.ir

1 Department of IT and Computer Engineering, Urmia Branch, Islamic Azad University, 57169-63896 Urmia, Iran

2 Department of IT, Faculty of Electrical and Computer Engineering, University of Tabriz, 51666-16471 Tabriz, Iran

3 Department of Remote Sensing and GIS, University of Tabriz, 57169-63896 Tabriz, Iran

4 Department of Computer Engineering, University College of Nabi Akram, 51839-18993 Tabriz, Iran 